\title{
The epidemiological and prognostic significance of the R/S Ratio in DIl derivation in patients with or without ST-segment elevation
}

\section{ST segment yükkselmesi olan veya olmayan hastalarda D II derivasyonunda R / S oranının epidemiyolojik ve prognostik önemi}

\author{
Sedat Özbay ${ }^{1}$, Abuzer Coşkunn ${ }^{1}$, Şevki Hakan $\mathbb{E}$ ren $^{2}$
}

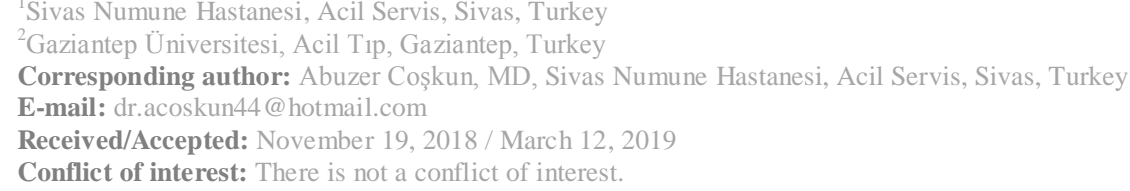

\section{SUMMARY}

Objective: The aim of this study was to evaluate the significance of R/S ratio (RSR) in the Lead II derivation of electrocardiography (ECG) in acute coronary syndrome (ACS) patients, in regards to the complications associated with myocardial infarction (MI), three-vessel coronary artery disease (TVCAD), and mortality.

Method: This cross-sectional retrospective cohort study included a total of 1102 patients with ACS, who presented to our hospital's emergency department (ED) with chest pain and were admitted to the cardiology inpatient service between January 2014 and December 2017. The patients with an RSR value less than 1 were assigned to group I and the patients with RSR values greater than 1 were assigned to group II. These groups were compared in terms of age and gender; the presence of blocked major coronary arteries (BMCA), complications associated with MI, and TVCAD; Gensini Scores (GS), the levels of cardiac troponin I (cTnI), and mortality rates.

Results: ST-segment elevation myocardial infarction (STEMI), unstable angina (UA), and non-ST segment elevation myocardial infarction (NSTEMI) were more frequent in group I in both genders. Ischemic heart failure (IHF), ventricular tachycardia (VT), acute pulmonary edema (APE), cardiac effusion (CE), and tamponade (CT) predominated in group I. However, atrioventricular (AV) block, TVCAD, and mortality was more frequent in group II. In men, STEMI, UA, NSTEMI, branch block (BB), complications, TVCAD, BMCA, and mortality were found to be high. Atrial fibrillation (AF) occurred more commonly in NSTEMI and BBB were more common in acute inferior MI (AIMI). IHF, VT, and APE were commonly seen in acute anterior MI (AAMI). AV block was more frequent in AIMI. TVCAD was more common and the mortality rate was higher in AAMI. The BMCA was identified to be the right coronary artery (RCA) in AIMI. The most commonly blocked vessels were the circumflex artery $(\mathrm{Cx}=\mathrm{L} 1)$ and the left anterior descending artery (LAD=L2) in AAMI. The most commonly blocked vessel was L2 in both UA and NSTEMI. Conclusions: The RSR value may become an adjunctive predictor for estimating the complications associated with MI, TVCAD, and mortality in ACS.

Keywords: Acute coronary syndrome, emergency department, mortality, RSR

\section{ÖZET}

Amaç: Akut koroner sendrom(ACS)'lu hastaların elektrokardiyografisinde(ECG) DII derivasyonunda R'ın S'e oranının(RSR), myokard infarktüsü(MI) sonrası oluşan komplikasyonlar, üç damar koroner arter hastalığı(TVCAD) ve mortalite açısından etkilerinin değerlendirilmesi amaçlanmıştır.

Yöntem: Bu retrospektif kesitsel kohort çalışmasına, Ocak 2014-Aralık 2017 tarihleri arasında hastanemiz acil servisine(ED) göğüs ağrısı nedeniyle başvuran ve kardiyoloji kliniğine yatırılan ACS'lu 1102 hastanın verileri dahil edildi. Hastalar RSR değerinin 1'den küçük olmasına grup 1, RSR değerinin 1'den büyük olmasına grup 2 denildi. Bu gruplar yaş, cinsiyet, tıkalı majör koroner damar(BMCA), Gensini Skoru (GS), MI sonrası oluşan komplikasyonlar, kardiyak troponin I (cTnI), TVCAD ve mortalite oranları açısından karşılaştıııldı. 
Bulgular: Her iki cinste de ST elevasyonlu MI(STEMI), unstabil angina(UA) ve non-ST elevasyonlu MI(NSTEMI) grup 1'de daha sıktı. Ayrıca iskemik kalp yetmezliği(IHF), ventriküler taşikardi(VT), akut akciğer ödemi(APE), kardiyak effüzyon(CE) ve tamponat(CT) yine grup 1'de ön plandaydı. Oysa atriyoventriküler(AV) blok, TVCAD ve mortalite grup 2'de daha sıktı. Erkeklerde STEMI, UA, NSTEMI, dal bloğu(BB), komplikasyonlar, TVCAD, BMCA ve mortalite fazla bulundu. Atrial fibfilasyon (AF) NSTEMI'da sıkken, BB akut inferior MI'da (AIMI) fazlaydı. IHF, VT, APE akut anterior MI(AAMI) sık tespit edildi. AV blok ise AIMI daha fazlaydı. TVCAD ve mortalite AAMI'da daha s1ktı. BMCA AIMI'da sağ koroner $\operatorname{arter}(\mathrm{RCA})$ iken, AAMI'da circumflex $\operatorname{arter}(\mathrm{Cx}=\mathrm{L} 1)$ ve left anterior descending $(\mathrm{LAD}=\mathrm{L} 2)$ 'i en sık tıkanan damarlardı. UA ve NSTEMI'da en s1k L2 tıkandığı tespit edildi.

Sonuç: ACS'da RSR düzeyleri MI sonrası gelişen komplikasyonlar, TVCAD ve mortalite açısından prediktif yardımcı bir değer olabilir.

Anahtar sözcükler: Acute coronary syndrome; emergency department; mortality; TVCAD, RSR

\section{INTRODUCTION}

The early diagnosis and initiation of the treatment readily are of critical importance in acute coronary syndrome (ACS). Coronary artery disease (CAD) is the most common cause of mortality and morbidity in all countries. The advances in the treatment options and the increased span of the average life expectancy have led to an increase in the number of older patients with recurrent cardiovascular diseases ${ }^{1}$. The development of myocardial necrosis has been reported in animal studies after the blockage in the coronary arteries lasting longer than 30 minutes ${ }^{2}$. Every 30 -minute delay in starting the reperfusion therapy after the onset of symptoms will increase the mortality rates. Percutaneous coronary intervention is a revascularization method for ACS patients and it has more favorable effects in decreasing the mortality rates in high-risk patients compared to low-risk patients ${ }^{4}$. AMI develops due to a blockage in the coronary blood flow in the previously stenosed arteries due to atherosclerosis 5. Coronary atherosclerosis is recognized as a remarkably preventable disease, in which a delayed-onset is possible. CAD comprises a group of diseases, of which the incidences can be reduced when the risk factors are controlled.

Electrocardiography plays an important role in the diagnosis of ACS and the identification of highrisk patients. The size of the myocardial area at risk and the severity of ischemia are important in these patients. ECG can provide valuable information about the location and prognosis of the lesion to decide the type of coronary reperfusion therapy, as well as, it allows for making the diagnosis in ACS patients. In UA and NSTEMI, the number of derivations with STsegment depression and the degree of depression are critical criteria for prognosis. In STEMI, the following parameters indicate a larger area of necrosis and poor prognosis, including the number of the derivations with ST-segment elevation, the degree of the ST-segment elevation, a newly developing left bundle branch block (LBBB), right bundle branch block (RBBB) or left anterior hemiblock (LAHB), the number of derivations with reciprocal ST-segment depression along with ST elevations, and the number of derivations with Q wave s-8. $^{\text {6-8 }}$.

The connection of the body electrodes to ECG are called "derivations" and they determine the action potential of the heart. The derivation system of Einthoven consists of three bipolar electrodes (one positive and one negative pole or electrode) placed on the anterior surfaces of the right and left leg, and on the posterior surface of the left leg. These three derivations are aligned on the same plane and form the Einthoven triangle ${ }^{11}$. They are named as derivation I, derivation II, and derivation III. Since the derivation wave in the heart is spread from the right to the left and from cranial to caudal, Einthoven has placed the positive electrodes of these derivations on the left side of the body. Therefore, DI derivation is obtained by placing a positive electrode on the anterior of the left leg and a negative electrode on the anterior of the right leg. DII derivation is obtained by placing a positive electrode on the posterior of the left leg and a negative electrode on the anterior of the right forearm. Finally, DIII derivation is obtained by placing a positive electrode on the posterior of the left leg and a negative electrode is placed on the anterior of the right leg ${ }^{12}$.

Cardiac troponins $(\mathrm{cTn})$ are structural proteins involved in the regulation of skeletal and cardiac muscle contraction together with tropomyosin. cTnT, cTnI, and cTnC complexes are located in thin filaments and allow for the calcium-mediated interaction of actin and myosin. cTn are sensitive and specific markers of cardiac muscle damage. These proteins were recognized as the standard 
markers for the diagnosis of AMI and for the diagnosis and monitoring of UA by the European Society of Cardiology/American College of Cardiology (ESC/ACC) and ACC/ American Heart Association (AHA) respectively ${ }^{13-16}$.

Although a number of previous studies examined the relationship of ACS with LAHB and left posterior hemiblock (LPHB) individually, we could not find any studies in the literature, investigating both types of hemiblock and RSR based on the DII derivation. In our study, we aimed to evaluate the STEMI subgroups, which are AIMI and AAMI, NSTEMI and UA, with the RSR and cTnI values in regards to the complications associated with AMI, TVCAD, and mortality.

\section{MATERIAL AND METHODS}

\section{I.Study design and population}

A total of 1102 patients, consisting of 396 females and 706 males with the mean age of $63.67 \pm 10.55$ (26-82) years, who presented to the Emergency Department of the Sivas Numune Hospital between January 2014 and December 2017 with chest pain and who were admitted to the Cardiology Clinic with the pre-diagnosis of ACS were retrospectively included in the study. The patients were excluded if the biochemistry tests, haemogram or a 12-lead ECG was not performed in the emergency department (ED); or if they did not have their angiographies or echocardiographic taken after the admission to the cardiology department. The patients were high-risk UA patients according to the Braunwald classification and the subgroups of STEMI, which were AIMI, AAMI, and NSTEMI groups ${ }^{17}$. The patients with an RSR value less than 1 were assigned to group I and the patients with RSR values greater than 1 group were assigned to group II. These groups were compared in terms of age, gender, the levels of cTnI, TVCAD, GS, and mortality. The levels of cTnI were tested at hour zero, hour 6 , and hour 12 after the ED admission and recorded as troponin I, II, III respectively.

The patients who had chest pain and/or discomfort lasting at least 30 minutes, had findings of STEMI in the ECG and diagnosed in accordance with the 2013 ACCF/AHA guidelines, were included in the study ${ }^{18}$. UA/NSTEMI is diagnosed according to the criteria of the 2014 AHA/ACC Guideline for the Management of Patients With NSTE-ACS. Transthoracic Echocardiography (TTE) was performed in all patients to determine the presence of focal wall-motion abnormalities. A
Philips Epiq 7 Ultrasound Machine was used to perform TTE in this study.

All patients participating in the study provided their written informed consents. The study was approved by the Ethics Committee of the Cumhuriyet University, Faculty of Medicine.

The study was conducted in compliance with the Declaration of Helsinki for medical research involving human subjects and was approved by the institutional review board.

The demographic, clinical, and laboratory data of the study patients were retrospectively reviewed using the medical records in the hospital, starting from their admission to ED due to ACS.

The haemograms were performed using a Beckman Coulter Automated CBC Analyzer (Beckman Coulter, Inc., Fullerton, CA, USA).

Biochemistry tests in blood were analyzed with the Cobas 6000 ( C6000-Core, Cobas c-501 series, Hitachi, Roche, USA). Performing the haemogram and biochemistry tests took 45-60 minutes.

\section{Cardiac Biomarker Analysis}

The venous blood samples were obtained from the antecubital veins of the patients to measure the serum levels of cTnI using STAT Elecsys and Cobas e 411 Hitachi Roche analyzers. The cTnI levels of the patients were measured at the 0th, 6 th and 12th hour of the ED admission.

\section{Electrocardiography}

12-lead ECG was performed at the bedside with Cardiofax ECG-9132K (Nihon Kohden, Tokyo, Japan) at the time of admission to the ED.

\section{Angiographic Analysis}

Angiographic evaluations were performed by two experienced cardiologists who were blinded to the study. Discrepancies were resolved by consensus. The extent and severity of CAD were assessed by Gensini Scoring (GS) System (19).

\section{Gensini Scoring System}

GS was calculated by multiplying the severity coefficient with the coefficient identified based on the functional importance of the myocardial area supplied by that segment. The severity coefficient was determined according to the degree of luminal narrowing as diameter reductions of $25 \%$, $50 \%, 75 \% 90 \%, 99 \%$, and $100 \%$ were given Gensini scores of 1, 2, 4, 8, 16, and 32, respectively). The coefficient determining the functional importance of the myocardial area 
supplied by the respective segment was determined as follows: the left main coronary artery, 5; the proximal segment of the left anterior descending coronary artery, 2.5; the mid segment of the left anterior descending coronary artery, 1.5; the apical segment of the left anterior descending coronary artery, 1 ; the first diagonal branch, 1; the second diagonal branch, 0.5; the proximal segment of the circumflex artery, 2.5 (if a right coronary artery dominance existed, the coefficient would be 3.5); the distal segment of the circumflex artery, 1 (if dominant, 2); the obtuse marginal branch, 1; the posterolateral branch, 0.5; the proximal segment of the right coronary artery, 1 ; the mid segment of the right coronary artery, 1; the distal segment of the right coronary artery, 1; and the posterior descending artery, $1^{22}$.

\section{Statistical Analysis}

The data were analyzed with the SPSS 15 software package. Based on the sample size, the Shapiro-Wilk test was used to determine whether the variables conform to a normal distribution. The Mann-Whitney U test and Kruskal Wallis-H test were used to determine the differences between the groups as the variables did not conform to a normal distribution. When significant differences were detected with the Kruskal Wallis-H test, a post-Hoc multiple comparison tests was performed to identify the groups with differences between. The chi-square analysis was carried out in analyzing the correlations between the groups of nominal variables. The Fisher's Exact Test was used when the expected values in the cells of the $2 \times 2$ tables were not of sufficient size, and the Spearman correlation analysis was carried out in the $\mathrm{RxC}$ tables using Monte Carlo Simulation. The results were interpreted at a significance level of 0.05 , considering $\mathrm{P}$ values less than 0.05 as statistically significant.

\section{RESULTS}

The clinical and demographic characteristics of the patients are listed in Table 1.

According to the results of the chi-square analysis of RSR; STEMI, UA, and NSTEMI were more frequent in group I in both genders. In addition, $\mathrm{AF}, \mathrm{BB}, \mathrm{IHF}, \mathrm{VT}, \mathrm{APE}, \mathrm{CE}$, and CT were also predominated in group I. However; AV block, TVCAD, and mortality were more common and statistically significant in the group II $(\mathrm{p}<0.05$, Table 2).

Table 1: Baseline characteristics of study patients.

\begin{tabular}{|c|c|c|c|c|c|}
\hline \multicolumn{6}{|c|}{ Acute Coronary Syndrome } \\
\hline & All patients & $\begin{array}{c}\text { Patients with } \\
\text { RSR }>1\end{array}$ & $\begin{array}{c}\text { Patients with } \\
\text { RSR }<1\end{array}$ & \multirow[t]{2}{*}{$\mathbf{Z}$} & \multirow{2}{*}{$\begin{array}{c}\text { p- } \\
\text { value }\end{array}$} \\
\hline & n:1102 \pm SD & $\mathrm{n}: 310 \pm \mathrm{SD}$ & n:792 \pm SD & & \\
\hline Mean age(y) & $63,67 \pm 10,55$ & $63,26 \pm 11,02$ & $63,83 \pm 10,36$ & $-0,507$ & $0,001 *$ \\
\hline Famale & $396(\% 35,9)$ & $93(\% 8,4)$ & $303(\% 27,5)$ & \multirow[t]{2}{*}{ 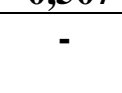 } & \multirow[t]{2}{*}{$0,002 *$} \\
\hline Male & $706(\% 64,1)$ & $217(\% 19,7)$ & $489(\% 44,4)$ & & \\
\hline LVEF & $51,00 \pm 13,23$ & $48,18 \pm 12,21$ & $52,11 \pm 13,46$ & $-4,806$ & $\mathbf{0 , 0 0 1 *}$ \\
\hline GS & $36,80 \pm 37,73$ & $44,32 \pm 37,49$ & $33,85 \pm 37,44$ & $-5,490$ & $0,001 *$ \\
\hline BMCA \% & $65,08 \pm 36,85$ & $77,81 \pm 32,50$ & $60,10 \pm 37,27$ & $-8,402$ & 0,001* \\
\hline cTn I & $1,97 \pm 4,02$ & $2,39 \pm 3,42$ & $1,8 \pm 4,22$ & $-5,751$ & $\mathbf{0 , 0 0 1} *$ \\
\hline cTn II & $4,87 \pm 7,26$ & $6,20 \pm 8,32$ & $4,35 \pm 6,75$ & $-6,762$ & $\mathbf{0 , 0 0 1} *$ \\
\hline cTn III & $11,52 \pm 15,72$ & $14,92 \pm 16,90$ & $10,18 \pm 15,04$ & $-6,668$ & $0,001 *$ \\
\hline TG(mg/dl) & $138,83 \pm 83,79$ & $140,98 \pm 90,55$ & $137,98 \pm 81,03$ & $-0,142$ & 0,057 \\
\hline Chol(mg/dl) & $170,90 \pm 59,74$ & $175,70 \pm 66,79$ & $169,02 \pm 56,67$ & $-1,202$ & 0,113 \\
\hline HDL(mg/dl) & $34,11 \pm 9,46$ & $34,72 \pm 9,76$ & $33,87 \pm 9,34$ & $-1,171$ & 0,526 \\
\hline LDL(mg/dl) & $27,86 \pm 17,29$ & $109,43 \pm 40,96$ & $106,79 \pm 49,59$ & $-1,853$ & 0,197 \\
\hline VLDL(mg/dl) & $27,86 \pm 17,29$ & $27,44 \pm 15,88$ & $28,02 \pm 17,82$ & $-0,298$ & 0,057 \\
\hline BS (mg/dl) & $136,00 \pm 64,44$ & $136,73 \pm 66,31$ & $135,71 \pm 63,74$ & $-0,448$ & 0,506 \\
\hline CK (U/L) & $134,57 \pm 108,23$ & $142,33 \pm 112,33$ & $131,53 \pm 106,50$ & $-2,117$ & 0,707 \\
\hline CK-MB(U/L) & $32,33 \pm 25,45$ & $33,69 \pm 25,35$ & $31,80 \pm 25,49$ & $-1,491$ & 0,553 \\
\hline Amylase U/L & $78,18 \pm 37,09$ & $82,15 \pm 39,73$ & $76,61 \pm 35,90$ & $-2,042$ & 0,666 \\
\hline CRP & $1,88 \pm 2,81$ & $1,79 \pm 2,85$ & $1,91 \pm 2,79$ & $-1,197$ & 0,112 \\
\hline
\end{tabular}




\begin{tabular}{|l|c|c|c|c|c|}
\hline WBC(10^3/uL) & $10,07 \pm 3,61$ & $9,87 \pm 3,55$ & $10,15 \pm 3,64$ & $-0,332$ & 0,208 \\
\hline MCV & $88,71 \pm 7,71$ & $88,81 \pm 7,79$ & $88,68 \pm 7,69$ & $-0,244$ & 0,647 \\
\hline MCH & $29,33 \pm 2,30$ & $29,29 \pm 2,46$ & $29,34 \pm 2,24$ & $-0,241$ & 0,191 \\
\hline MCHC g/dL & $32,86 \pm 0,75$ & $32,87 \pm 0,70$ & $32,86 \pm 0,77$ & $-0,579$ & 0,308 \\
\hline RDW (\%) & $15,00 \pm 2,32$ & $15,00 \pm 2,21$ & $15,00 \pm 2,37$ & $\mathbf{- 8 , 2 2 6}$ & $\mathbf{0 , 0 0 1} *$ \\
\hline PLT & $246,25 \pm 74,05$ & $237,62 \pm 77,57$ & $249,63 \pm 72,40$ & $-1,178$ & 0,239 \\
\hline MPV fL & $8,50 \pm 1,34$ & $8,65 \pm 0,86$ & $8,44 \pm 1,27$ & $\mathbf{- 2 , 7 2 5}$ & $\mathbf{0 , 0 0 6} *$ \\
\hline Neu \% & $7,21 \pm 3,56$ & $7,42 \pm 3,84$ & $7,13 \pm 3,44$ & - & $\mathbf{0 , 0 0 1}$ \\
& & & & $\mathbf{1 9 , 7 6 6}$ & \\
\hline Lymph \% & $2,15 \pm 1,17$ & $2,18 \pm 1,22$ & $2,13 \pm 1,15$ & $-0,678$ & 0,498 \\
\hline
\end{tabular}

ACS: Acute Coronary Syndrome, LVEF: Left Ventricular Ejection Fraction, GS: Gensini Score, BMCA:Bloced Major Coronary Artery

cTn: Cardiac Troponin, TG: Triglycerides, Chol: Cholesterol, HDL: high density lipoprotein, LDL: low density lipoprotein, VLDL: Very-low-density lipoprotein, BS:Blood Suger, CK: Creatine Kinase, CK-MB: Creatine Kinase Muscle Brain, CRP: C-Reactive Protein, WBC: White Blood Cells, MCV: Mean Corpuscular Volume, MCH: Mean Corpuscular Hemoglobin, MCHC: Mean Corpuscular Hemoglobin Concentration, RDW: Red Cell Distribution Width, PLT: Platelets, MPV:Mean Platelate Volum; Neu:Neutrophil; Lymph: lymphocyte ${ }^{*} p<0.05$

Table 2: Chi-square analysis of RSR groups according to acute coronary syndrome variables

\begin{tabular}{|c|c|c|c|c|c|c|}
\hline \multicolumn{7}{|c|}{ Acute Coronary Syndrome } \\
\hline \multirow[t]{2}{*}{ RSR } & \multirow{2}{*}{\multicolumn{2}{|c|}{\begin{tabular}{|c|r|} 
Patients with & \multicolumn{1}{c|}{ RSR>0,1 } \\
n:310
\end{tabular}}} & \multicolumn{2}{|c|}{ Patients with } & \multirow[t]{2}{*}{$\chi^{2}$} & \multirow[t]{2}{*}{ p-value } \\
\hline & & & n:792 & $\% 100$ & & \\
\hline Famale & 93 & 30,0 & 303 & 38,3 & \multirow[t]{2}{*}{6,60} & \multirow[t]{2}{*}{$\mathbf{0 , 0 1 0 *}$} \\
\hline Gender & 217 & 70,0 & 489 & 61,7 & & \\
\hline \multirow{4}{*}{$\begin{array}{r}\text { UA } \\
\text { AIMI } \\
\text { AAMI } \\
\text { NSTEMI }\end{array}$} & 67 & 21,6 & 360 & 45,5 & \multirow{4}{*}{275,18} & \multirow{4}{*}{$0,001 *$} \\
\hline & 157 & 50,6 & 55 & 56,9 & & \\
\hline & 52 & 16,8 & 244 & 30,8 & & \\
\hline & 34 & 11,0 & 133 & 16,8 & & \\
\hline \multirow[t]{2}{*}{$\mathbf{A F}$} & 239 & 77,1 & 649 & 81,9 & \multirow[t]{2}{*}{10,26} & \multirow[t]{2}{*}{ 0,006* } \\
\hline & 71 & 22,9 & 143 & 18,1 & & \\
\hline \multirow[t]{3}{*}{ Branch Block } & 165 & 53,2 & 519 & 65,5 & \multirow{3}{*}{38,14} & \multirow{3}{*}{$0,001 *$} \\
\hline & 97 & 31,3 & 118 & 14,9 & & \\
\hline & 48 & 15,5 & 155 & 19,6 & & \\
\hline \multirow[t]{6}{*}{ Complikation } & 98 & 31,6 & 446 & 56,3 & \multirow{6}{*}{84,94} & \multirow{6}{*}{$0,001 *$} \\
\hline & 129 & 41,6 & 213 & 26,9 & & \\
\hline & 14 & 4,5 & 56 & 7,1 & & \\
\hline & 35 & 11,3 & 19 & 2,4 & & \\
\hline & 8 & 2,6 & 15 & 1,9 & & \\
\hline & 26 & 8,4 & 43 & 5,4 & & \\
\hline \multirow[t]{2}{*}{ TVCAD } & 216 & 69,7 & 623 & 78,7 & \multirow[t]{2}{*}{9,90} & \multirow[t]{2}{*}{ 0,002* } \\
\hline & 94 & 30,3 & 169 & 21,3 & & \\
\hline \multirow[t]{2}{*}{ Mortality } & 249 & 80,3 & 718 & 90,7 & \multirow[t]{2}{*}{22,13} & \multirow[t]{2}{*}{ 0,001* } \\
\hline & 61 & 19,7 & 74 & 9,3 & & \\
\hline
\end{tabular}

UA: Unstable Angina, AIMI: Acute Inferior Myocardial Infarction, AAMI: Acute Anterior Myocardial Infarction, NSTEMI: Non ST elevation myocardial infarction, AF: Atrial Fibrillation, RBB: Right Branch Block, LBB:Left Branch Block, IHF: Ischemic Heart Failure, VT:Ventricular Tachycardia, AV: Atrioventricular, CE: Cardiac Effusion, CT: Cardiac Tamponade, APE: Acute Pulmonary Edema, TVCAD: Three-vessels Coronary Artery Disease $*_{p}<0.05$

According to the chi-square analysis of RSR, BMCA analysis was statistically significant $(\mathrm{p}<0.05$, Table 3$)$.

The chi-square analysis of RSR groups by sex showed that UA, AIMI, AAMI, and NSTEMI were more common in men $(p<0.05)$. The frequency of $\mathrm{AF}$ was not significantly different in men ( $p>0.05$ ), BB, complications, TVCAD, BMCA and mortality ( $<<0.05$, Table 4$)$. 
Table 3: Analysis of acute coronary syndrome in RSR groups according to gender diagnosis and complications

\begin{tabular}{|c|c|c|c|c|c|c|}
\hline \multicolumn{6}{|c|}{ Acute Coronary Syndrome } & \multirow[b]{3}{*}{ p-value } \\
\hline \multirow[t]{2}{*}{ Gender } & \multicolumn{2}{|c|}{ Famale } & \multicolumn{2}{|c|}{ Male } & \multirow[b]{2}{*}{$\gamma 2$} & \\
\hline & $n: 396$ & $\% 100$ & n:706 & $\% 100$ & & \\
\hline \multirow{4}{*}{ 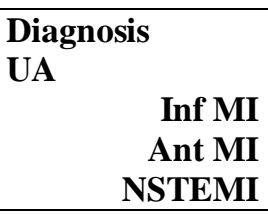 } & 198 & 50,0 & 229 & 32,4 & \multirow{4}{*}{40,92} & \multirow{4}{*}{ 0.001* } \\
\hline & 58 & 14,6 & 154 & 21,8 & & \\
\hline & 76 & 19,2 & 220 & 31,2 & & \\
\hline & 64 & 16,2 & 103 & 14,6 & & \\
\hline \multirow{2}{*}{$\begin{array}{l}\mathbf{A F} \\
\text { No }\end{array}$} & 325 & 82,1 & 563 & 79,7 & \multirow[t]{2}{*}{0,99} & \multirow[t]{2}{*}{0,607} \\
\hline & 71 & 17,9 & 143 & 20,3 & & \\
\hline \multirow{3}{*}{$\begin{array}{l}\text { Branch Block } \\
\text { No } \\
\\
\text { RBB } \\
\text { LBB }\end{array}$} & 261 & 65,9 & 423 & 59,9 & \multirow[t]{3}{*}{10,31} & \multirow[t]{3}{*}{ 0,006* } \\
\hline & 57 & 14,4 & 158 & 22,4 & & \\
\hline & 78 & 19,7 & 125 & 17,7 & & \\
\hline \multirow{6}{*}{$\begin{array}{l}\text { Complikation } \\
\text { No } \\
\\
\text { IHF } \\
\text { VT } \\
\text { AV Block } \\
\text { CE/CT } \\
\text { APE }\end{array}$} & 232 & 58,6 & 312 & 44,2 & \multirow{6}{*}{27,96} & \multirow{6}{*}{$\mathbf{0 , 0 0 1 *}$} \\
\hline & 110 & 27,8 & 232 & 32,9 & & \\
\hline & 15 & 3,8 & 55 & 7,8 & & \\
\hline & 12 & 3,0 & 42 & 5,9 & & \\
\hline & 10 & 2,5 & 13 & 1,8 & & \\
\hline & 17 & 4,3 & 52 & 7,4 & & \\
\hline \multirow{2}{*}{$\begin{array}{l}\text { TVCAD } \\
\text { No }\end{array}$} & 327 & 82,6 & 512 & 72,5 & \multirow[t]{2}{*}{14,11} & \multirow[t]{2}{*}{ 0,001* } \\
\hline & 69 & 17,4 & 194 & 27,5 & & \\
\hline \multirow{2}{*}{$\begin{array}{l}\text { Mortality } \\
\text { No }\end{array}$} & 364 & 91,9 & 603 & 85,4 & \multirow[t]{2}{*}{10,00} & \multirow[t]{2}{*}{$0,002 *$} \\
\hline & 32 & 8,1 & 103 & 14,6 & & \\
\hline
\end{tabular}

${ }^{*} p<0.05$

Table 4: Analysis of acute coronary syndrome diagnoses in RSR groups according to complications and variables

\begin{tabular}{|c|c|c|c|c|c|c|c|c|c|c|}
\hline \multicolumn{11}{|c|}{ Acute Coronary Syndrome } \\
\hline \multirow[t]{2}{*}{ Diagnosis } & \multicolumn{2}{|c|}{ UA } & \multicolumn{2}{|c|}{ AIMI } & \multicolumn{2}{|c|}{ AAMI } & \multicolumn{2}{|c|}{ NSTEMI } & \multirow{2}{*}{$\chi^{2}$} & \multirow{2}{*}{ p-value } \\
\hline & n:427 & $100 \%$ & $n: 212$ & $100 \%$ & n:296 & $100 \%$ & n:167 & $100 \%$ & & \\
\hline \multirow{2}{*}{$\begin{array}{lr}\text { Complikation } & \begin{array}{r}\text { No } \\
\text { IHF }\end{array}\end{array}$} & 330 & 77,3 & 86 & 40,6 & 65 & 22,0 & 63 & 37,7 & \multirow{6}{*}{372,95} & \multirow{6}{*}{$\mathbf{0 , 0 0 1 *}$} \\
\hline & 61 & 14,3 & 65 & 30,7 & 150 & 50,7 & 66 & 39,5 & & \\
\hline \multirow{4}{*}{$\begin{array}{r}\mathrm{VT} \\
\mathrm{AV} \text { Block } \\
\mathrm{CE} / \mathrm{CT} \\
\mathrm{APE}\end{array}$} & 9 & 2,1 & 7 & 3,3 & 35 & 11,8 & 19 & 11,4 & & \\
\hline & 8 & 1,9 & 40 & 18,9 & 3 & 1,0 & 3 & 1,8 & & \\
\hline & 8 & 1,9 & 4 & 1,9 & 5 & 1,7 & 6 & 3,6 & & \\
\hline & 11 & 2,6 & 10 & 4,7 & 38 & 12,8 & 10 & 6 & & \\
\hline \multirow{2}{*}{$\begin{array}{ll}\text { AF } & \text { No } \\
& \text { Yes } \\
\end{array}$} & 357 & 83,6 & 159 & 75,0 & 250 & 84,5 & 115 & 68,9 & \multirow[t]{2}{*}{$\mathbf{5 0 , 7 5}$} & \multirow[t]{2}{*}{ 0,001* } \\
\hline & 70 & 16,4 & 53 & 25,0 & 46 & 15,5 & 52 & 31,1 & & \\
\hline \multirow{3}{*}{$\begin{array}{rr}\text { Branch Block } & \text { No } \\
\text { RBB } \\
\text { LBB }\end{array}$} & 306 & 71,7 & 115 & 54,2 & 168 & 56,8 & 95 & 56,9 & \multirow{3}{*}{35,35} & \multirow{3}{*}{ 0,001* } \\
\hline & 58 & 27,0 & 61 & 28,4 & 62 & 28,8 & 34 & 20,4 & & \\
\hline & 63 & 14,8 & 36 & 17,7 & 66 & 22,3 & 38 & 22,8 & & \\
\hline \multirow[t]{2}{*}{ TVCAD } & 423 & 99,1 & 165 & 77,8 & 133 & 44,9 & 118 & 70,7 & \multirow[t]{2}{*}{285,24} & \multirow[t]{2}{*}{$0,001 *$} \\
\hline & 4 & 0,9 & 47 & 22,2 & 163 & 55,1 & 49 & 29,3 & & \\
\hline \multirow[t]{2}{*}{ Mortality } & 413 & 96,7 & 176 & 83,0 & 238 & 80,4 & 140 & 83,8 & \multirow[t]{2}{*}{53,62} & \multirow[t]{2}{*}{ 0,001* } \\
\hline & 14 & 3,3 & 36 & 17,0 & 58 & 19,6 & 27 & 16,2 & & \\
\hline
\end{tabular}


According to the chi-square analysis of RSR groups; AF was most commonly seen in the IAMI associated with NSTEMI. While BBB is frequently seen with AIMI; IHF, VT, and APE were more frequently associated with AAMI. AV block was more common in patients with IAMI.
TVCAD and mortality rates were high in AAMI. BMCA was RCA in IAMI. In AAMI, L1 and L2 are the most frequently occluded vessels. L2 occlusion was found most frequently in UA and NSTEMI ( $p<0.05$, Table 5).

Table 5: Blocked Major Coronary Artery analysis of acute coronary syndromes

\begin{tabular}{|c|c|c|c|c|c|c|c|c|c|c|}
\hline \multicolumn{11}{|c|}{ ACS } \\
\hline \multirow[b]{2}{*}{ Tanı } & \multicolumn{2}{|c|}{ UA } & \multicolumn{2}{|c|}{ AIMI } & \multicolumn{2}{|c|}{ AAMI } & \multicolumn{2}{|c|}{ NSTEMI } & \multirow[t]{2}{*}{$\chi^{2}$} & \multirow[t]{2}{*}{ p-value } \\
\hline & n:427 & $100 \%$ & n:212 & $100 \%$ & $n: 296$ & $100 \%$ & n:167 & $100 \%$ & & \\
\hline RCA & 83 & 19,4 & 74 & 34,9 & 18 & 6,1 & 24 & 14,4 & \multirow{14}{*}{$\begin{array}{c}22 \\
1, \\
42\end{array}$} & \multirow{14}{*}{$0,001 *$} \\
\hline R1 & 15 & 3,5 & 8 & 3,8 & 0 & 0 & 7 & 4,2 & & \\
\hline $\mathbf{R 2}$ & 21 & 4,9 & 12 & 5,7 & 0 & 0 & 4 & 2,4 & & \\
\hline R3 & 21 & 4,9 & 17 & 8,0 & 7 & 2,4 & 4 & 2,4 & & \\
\hline R4 & 12 & 2,8 & 11 & 5,2 & 7 & 2,4 & 10 & 6,0 & & \\
\hline $\mathbf{L}$ & 48 & 11,2 & 6 & 2,8 & 15 & 5,1 & 13 & 7,8 & & \\
\hline L1 & 48 & 11,2 & 33 & 15,6 & 53 & 17,9 & 28 & 16,8 & & \\
\hline L2 & 87 & 20,4 & 23 & 10,8 & 133 & 44,9 & 40 & 24,0 & & \\
\hline L1A & 24 & 5,6 & 4 & 1,9 & 15 & 5,1 & 7 & 4,2 & & \\
\hline L1B & 15 & 3,5 & 8 & 3,8 & 4 & 1,4 & 4 & 2,4 & & \\
\hline L1C & 8 & 1,9 & 1 & 0,5 & 5 & 1,7 & 10 & 6,0 & & \\
\hline L2A & 28 & 6,6 & 9 & 4,2 & 22 & 7,4 & 8 & 4,8 & & \\
\hline L2B & 13 & 1,2 & 3 & 1,4 & 11 & 3,7 & 5 & 3,0 & & \\
\hline L2C & 4 & 0,9 & 3 & 1,4 & 6 & 2,0 & 3 & 1,8 & & \\
\hline
\end{tabular}

$* p<0.05$

According to BMCA chi-square analysis of RSR groups; The most frequent AF, L2 ( $\mathrm{n}=46 ; 4.2 \%)$ and RCA ( $\mathrm{n}=43 ; 3.9 \%)$; BBB was more prevalent in relation to occlusion of $\mathrm{L} 2(\mathrm{n}=65$; $5.9 \%)$ and RCA $(\mathrm{n}=43 ; 3.9 \%)$. However, the results were not statistically significant $(\mathrm{p}>0.05)$.
Statistical analysis of complications showed that IHF, VT, CE and CT were more common in L2, AV block was more common in RCA and APE was more common in L1. TVCAD and mortality were most frequently found in L2 ( $p<0.05$, Table $6)$.

Table 6: Friedman's Two Way ANOVA Test for Differences Between Times in Terms of Troponin Values in RSR Groups

\begin{tabular}{|c|c|c|c|c|c|c|c|c|c|c|}
\hline \multicolumn{10}{|c|}{ Friedman's Two Way ANOVA } & \multirow{2}{*}{ Çoklu Karşılaştırma } \\
\hline & & & $\mathrm{n}$ & Mean & Min & Max & SD & $\chi^{2}$ & p-value & \\
\hline \multirow{6}{*}{ RSR } & \multirow{3}{*}{$\operatorname{RSR}<0,1$} & 0.h cTn & & 1,81 & 0,00 & 95 & 4,23 & \multirow{3}{*}{1203,18} & \multirow{3}{*}{$0,001 *$} & \multirow{3}{*}{$1-21-32-3$} \\
\hline & & 6. h cTn & 792 & 4,35 & 0,00 & 57,20 & 6,73 & & & \\
\hline & & 12. h cTn & & 10,18 & 0,01 & 100 & 15,04 & & & \\
\hline & \multirow{3}{*}{$\mathrm{RSR}>0,1$} & 0. h cTn & & 2,39 & 0,00 & 40,2 & 3,42 & \multirow{3}{*}{621,605} & \multirow{3}{*}{$0,001 *$} & \multirow{3}{*}{$1-21-32-3$} \\
\hline & & 6. h cTn & 310 & 6,20 & 0,01 & 100 & 8,32 & & & \\
\hline & & $12 \mathrm{~h} \mathrm{cTn}$ & & 14,92 & 0,01 & 100 & 16,90 & & & \\
\hline
\end{tabular}


Tablo7 : Spearman correlation coefficients for RSR groups

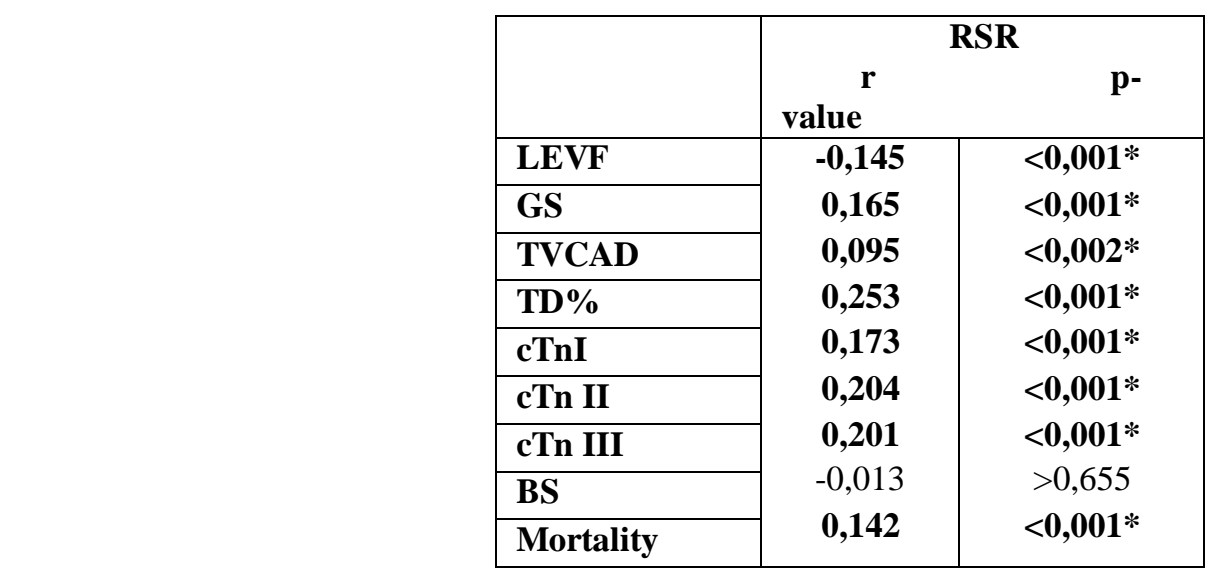

$*_{p}<0.05$

Spearman's correlation analysis showed statistically significant differences between the groups ( $\mathrm{p}<0.05$, Table 7$)$.

\section{DISCUSSION}

There are several studies available in the literature, investigating ACS, LAHB, and LPHB either individually or together. However, we could not find any studies in the literature about RSR based on the lead II derivation. Only a few studies examined the findings in II lead of ECG at the time of ED admissions in relation with the STEMI subgroups, NSTEMI, UA, complications associated with ACS, TVCAD, and mortality. Therefore, we conducted our study in order to determine these correlations.

In LAHB, the posteroinferior region of the left ventricle endocardium is abnormally activated

before the anterosuperior region. After the stimulus leaves the posteroinferior fascicle of the left bundle branch, it progresses to the right and to the inferior, and usually the anterior directions for a short time, producing a $\mathrm{Q}$ wave in the leads I and aVL, and an R wave in the leads II, III and aVF (Figure 1). In LPHB, the stimulus leaves the bundle brunch at the anterosuperior division, creating small Q waves in II, III, and aVF leads. The stimulus then progresses to the inferior direction and to the right in the electrically dominant left ventricle. This explains the $\mathrm{S}$ wave in I and aVL; and the R waves found in the leads II, III, and aVF (20, 21) (Figure 2).

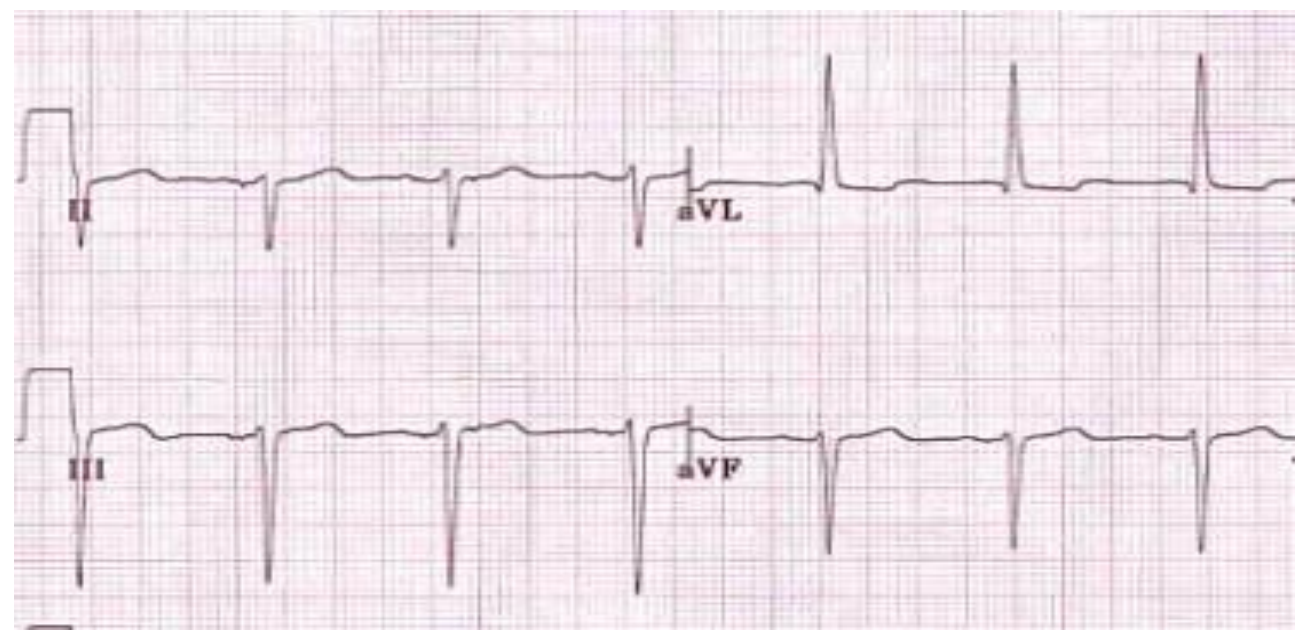

Figure 1: Left anterior hemiblock 


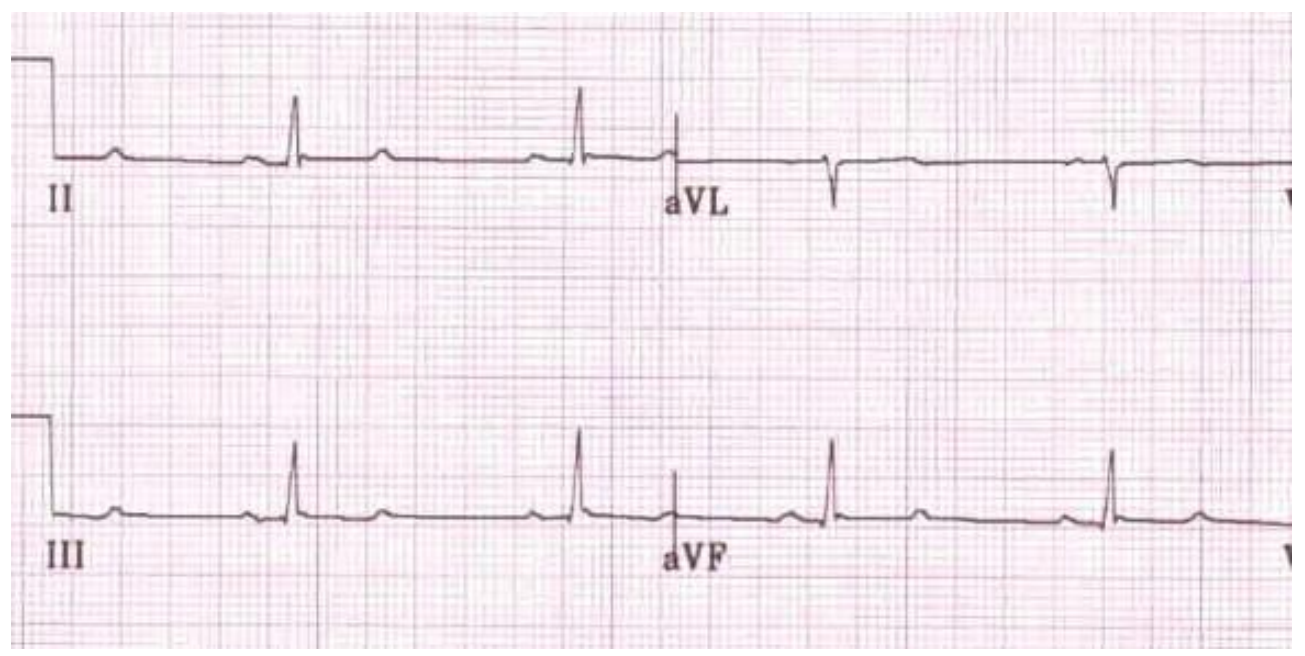

Figure 2: Left posterior hemiblock

In our study, DII derivation was used to determine the presence of LAHB and LPHB as these latter are determined in lead II, III, and aVF according to specific criteria. Therefore, the II lead includes both the hemiblocks and the R and $\mathrm{S}$ waves in the II leads without any blocks. II lead of ECG also shows the differences in the action potentials between the left arm and leg, which is equal to the total voltage of the I and II leads. Therefore, II is the lead showing the ECG waves most clearly. It is therefore used in diagnosing the cardiac rhythm disorders, in monitoring the cardiac rhythm, and in evaluating the ventricular hypertrophies. It shows inferior wall ischemia and possible $\mathrm{Cx}$ artery lesions in coronary artery diseases. Therefore, DII derivation was selected to be used in the study.

In a heart with a normal conduction system, the ventricular volume is determined based on the myocardial mass of the ventricles. For this reason, the mean electrical axis is calculated to determine whether the right or the left ventricle is dominant. In a healthy living organism, the left ventricle is three times larger than the right ventricle. As a result, a depolarization wave is observed in the ECG trace, mainly moving backward and to the left. Thus, large R waves are formed in leads DI, DII, DIII, and aVF ${ }^{22}$. In overt right-sided cardiomegaly, the right ventricular mass is greater than the left ventricular mass. As the right ventricle is more dominant, the depolarization wave moves forward and to the right in the ECG trace. As a result, deep $S$ waves are observed in the leads DI, DII, DIII, and aVF. The mean electrical axis shifts to the right and to the cranial direction ${ }^{23}$. The mean electrical axis may also shift in the intraventricular conduction system blocks ${ }^{24}$.
Male gender is independently accepted as a risk factor in several studies. Coronary artery diseases are seen in males at a rate of $60 \%$. Atherosclerotic heart diseases start developing 10-20 years earlier in male individuals with an incidence of 3-6 times higher than that of females (25). Of our study patients, $706(64.1 \%)$ were males and 396 (35.9\%) were females with a mean age of 63 years. These data were consistent with current studies.

In patients with ACS, cardiac markers such as cTnI, myoglobin, and CK-MB are important in confirming the diagnosis and in differentiating UA from NSTEMI. Elevated values of cTnI are important indicators in making the diagnosis of UA in high-risk cardiovascular patients with normal CK-MB levels, evaluated for a suspected ACS (26-28). cTnI and TnT are elevated in the reversible period of ischemia ${ }^{29}$. It is possible to identify ACS patients at risk with serial troponin measurements. In patients with high levels of cTn, it has been demonstrated that the risk of cardiac complications is higher, even if CK-MB levels are normal; and that troponins had a higher prognostic value compared to the patient's findings ${ }^{30,31}$. In the TIMI 18 study, patients with a higher cTn I level than the 99th percentile had a 3-fold higher risk of death or recurrent MI than those with a cTnI level of $<0.1 \mathrm{ng} / \mathrm{ml}^{32}$.

In our study, the cTnI levels at hour 0,6 , and 12 were significantly higher in group 2 than those in group 1. We found that the prognosis and mortality increased in group 2 with higher cTnI levels. cTn I elevations were observed significantly higher with complications of AMI, TVCAD, and mortality. While this elevation was the highest in the STEMI subgroups followed by that in the NSTEMI group, the lowest elevation was found in the UA group with the lowest degree 
of inflammation. These values were found in the univariate and multivariate time series analyses. The levels of cTnI were also positively correlated with the complications, TVCAD, and mortality. It is therefore extremely important to accurately and consistently detect the low troponin concentrations and small increases in their quantities in order to determine the critical threshold level for the follow-up and treatment, particularly in the diagnosis and prognosis of the ACS patients at risk. It is important to determine the decision-making limits for correct diagnosis in patients with ACS.

The incidence of observing RSR in the II leads have not been established yet. Even in LAHB and LPHB where RSR is $<1$ or $>1$, the incidence is variable depending on the presence of CAD. In the studies on LAHB in the literature; Marriott et al. ${ }^{33}$ reported the incidence as $15.2 \%$ in a 250 patient study, Scheinman et al. ${ }^{34}$ reported it as $4 \%$ in a 480-patient case series, Col et al. ${ }^{35}$ reported it as $6.2 \%$ in 225 patients. The frequency of an isolated LAHB was reported to be $9.9 \%$ in a 700 patient case series ${ }^{36}$. LAHB is rarely seen in patients without a history of MI, especially ${ }^{37}$. LAHB is common in acute MI patients. However, the published data is based on a limited number of patients followed-up for shorter periods. LAHB is a well-recognized complication of acute MI in 3$5 \%$ of patients. In patients with AIMI, LAHB was found to be associated with a large infarct extension and the left anterior descending CAD ${ }^{38,39}$. Because the left anterior fascicle is sensitive to very minor ischemic and necrotic alterations in the anterior descending artery due to its fine structure, LABH commonly occurs in AMI ${ }^{40-42}$.

Several studies on ECG report that LPHB occurs very rarely in the AMI patients compared to the other fascicular and branch blocks. The average incidence ranges from 0.2 to $0.4 \%$. Scheinman ${ }^{43}$ reported the incidence as $0.2 \%$ in one study and $0.4 \%$ in the other and Rizzon ${ }^{44}$ reported a $0.3 \%$ incidence. Similar to these studies, similar results have been reported in the literature. All studies share the same limitation of not performing anatomical and histological examinations in a sufficient number of patients. The first likely cause of this was reported by Rosenbaum et al. ${ }^{45}$ suggesting that the posterior of the left posterior bundle branch was the least sensitive part of all intraventricular conduction system. Because the blood supply comes from the branches of both the left and right coronary arteries, which are short and relatively large. The other possible cause is that if LPHB is incomplete, the ECG pattern will not show the characteristic features completely.
Therefore, it may be difficult or impossible to make a diagnosis unless the block is spontaneously formed. Finally, as the distribution of the left branch divisions can show variations, not everyone may have a separate posterior fascicle responsible for the Purkinje network in the inferior-posterior wall of the left ventricle ${ }^{46,47}$.

In this study, we did not determine the incidence as we did not focus our investigations only on the criteria of LAPH and LPHB. As II lead provides information about both of these two fascicles, we examined the gender, age, TVACD, and mortality based on RSR criteria. Although the number of study patients was higher in group I, the mean GS was low. Therefore the frequency of coronary artery involvement was low and its prognosis was found to be better compared to group II. In group II, the number of cases was low, the number of the involved coronary arteries was high, the mean EF was low, and the mean GS was high. the prognosis was determined to be worse compared to group I. In both groups, male gender was more frequent. In Group 1; AF, RBB, LBB, UA, AAMI, and STEMI were more frequent while AIMI was more prevalent in group 2. However, AV block, TVCAD, and mortality were more frequent in group II. We concluded that RSR of the DII lead could be used as an indicator in making a diagnosis and in predicting the prognosis in CAD, as well as in the follow-up of the patients.

The study by Corne et al. ${ }^{48}$, conducted on 390 males older than 30 years, reported an increased incidence of CAD in patients with LAHB when compared to the sex-matched controls. Similar studies reported an association between LAHB and the increased risk of cardiac death ${ }^{49-51}$. Intraventricular blocks associated with AMI have been studied extensively. These studies have shown that complete bundle branch blocks and incomplete fascicular blocks affect the prognosis of AMI unfavorably. Any conduction disorder developing during AMI is expected to increase the risk associated with the disease. In addition, it has been recognized that the occurrence of $\mathrm{RBB}$ or LBB increases the rate of mortality in AMI ${ }^{52-54}$. Castellanos et al., ${ }^{55}$ reported a high incidence of $\mathrm{AV}$ block in AMI in the presence of LPHB or RBBB. A bifascicular block was identified in some patients. In some other patients, a second or third-degree AV block was found (27\%). All these observations supported a linkage function instead of localizing the block in the ventricle. Regardless of the location of the complete AV block, it is highlighted that it may emerge as the primary 
complication in one patient or it may develop during a severe shock in the others.

Indicating the ACS-associated complications and myocardial injury, cTn I levels were low in the patients with UA with low inflammation levels in group I in our study. However, there were more findings in AAMI and NSTEMI, with a higher degree of inflammation, compared to UA. AIMI was high in group II. It was observed that the complications, TVCAD, and mortality were determined based on the types of MI. CT, CE, AF, and $\mathrm{BBB}$ were more common in males and in group I. BBB was more common in AAMI. In addition, hypertension, VT, APE, and IHF; commonly seen after the anterior wall MIs, were predominating in group I. This finding supports the fact that there is a tendency to develop hypertension, tachycardia, and VT during an anterior wall AMI. The frequency of 2nd and 3rd degree AV blocks in the presence of LPHB was similar to those reported in the literature in group II of our study. This finding is consistent with the tendency of inferior MI patients to develop hypotension, bradycardia, and complete block. BMCA was observed to be primarily RCA, LAD, and $\mathrm{Cx}$ arteries and the greater vessel structures including the right ventricular branch (R2) and LAD 2 in men. Diagonal artery (L1B) was observed to be commonly stenosed in women. RCA was found to be commonly stenosed in UA and AIMA. In AAMI, L1 was the most commonly stenosed artery followed by L1. In NSTEMI, L2 was stenosed most frequently. The prevalence and lesion severity of CAD is determined by evaluating GS. The patients with GS below 20 are categorized as having a mild CAD and the individuals with GS equal to or over 20 are categorized as severe CAD patients $(56,57)$. For the same purpose, GS was used in our study. A significant difference was found between the GS and LVEF values of RSR $<1$ or RSR > 1 group categorized according to the RSR values in the DII lead. The number of patients was lower, GS was higher, and the mean LVEF was lower in Group 2. It was seen that the higher the number of the involved coronary arteries, the higher would be the Gensini scores. It was also observed that the increased scores were associated with significantly decreased LVEF depending on the area of involvement in the heart. EF was lower in both groups but lower in group II compared to group I.

Development of LABH in AIMI was correlated with significant stenoses in LAD and also correlated with multiple vessel CAD. Assali et al. ${ }^{38}$ reported that of the 87 patients with AIMI,
LAHB developed in 17 (19\%) patients. Significant stenosis of LAD was found in $82 \%$ of the patients with LAHB and in $21 \%$ of patients the patients without LAHB. A 159 patient study by Biagini et al. (39) reported the frequency of LAHB as $13 \%$. The incidence of cardiac death was 2.5 times higher in patients with LAHB. During a mean of the 5-year follow-up period, the overall incidence of all-cause mortality was 1.5 fold higher in this patients group compared to the patients without LAHB. Isolated LAHB is an independent predictor of total and cardiac mortality in CAD patients without a history of MI. LPHB is almost always associated with severe $\mathrm{CAD}$, in which both the anterior and posterior blood supply to the ventricular septum is unfavorably affected. A resulting wide ischemic injury covering the majority of the ventricular septum or covering at least two-thirds of the middle and posterior ventricular septum, as well as the distribution of the inferior left bundle branch and its radiations in the septum and the acute histopathological changes of the left conduction system, would affect not only the posterior septal fascicles but also the midseptal fascicles to some extent. A two- or three-vessel CAD leads to a severe insult in the cardiac tissue, leading to the development of an area of infarction involving the whole septum or covering a large area of it as confirmed with anatomical findings ${ }^{36}$, 58-61. LPHB, alone or in association with RBB, is an early complication because it occurs within a few hours or sometimes in several minutes after the onset of an acute attack. The LPHB is considered to be an ominous sign because of the $87 \%$ mortality rate. Death occurs within 48 hours following the onset of AMI as a result of the developing shock either alone or in association with acute left ventricular failure. Therefore, our findings prove that mortality is primarily related to an early manifestation of a serious pumping failure. This manifestation can readily be explained by postmortem findings indicating a severe two- or three-vessel CAD and a large area of myocardial infarction. The high mortality rates were consistent with those reported in similar studies ${ }^{36,55,58.62}$.

In our study, TVCAD was detected in 263 (23.8\%) patients out of 1102 . Of these patients with TVCAD, 169 (21.3\%) were in group I and $94(30.3 \%)$ were in group II. Of them, 194 $(27.5 \%)$ were men and $69(17.4 \%)$ were women. TVCAD was found in $4(0.4 \%)$ patients in the UA group, in $47(4.3 \%)$ patients in AIMI, in 163 (14.8\%) patients in AAMI, and in $49(4.4 \%)$ in NSTEMI. The blocked arteries were most 
commonly L2, L1, and RCA respectively in the order of decreasing frequency. In ACS patients, a value of RSR>1 in the DII lead is of prognostic significance for TVCAD. These findings suggest that a value of RSR>1 is a more favorable predictor in an extensive and severe myocardial ischemia compared to an $\mathrm{RSR}<1$ seen in the other leads. Mortality occurred in 135 (12.2\%) patients out of 1102 patients. Of these patients, 74 (9.3\%) were in group I and $61(19.7 \%)$ were in group II. Mortality occurred in 103 (14.6\%) males and 32 $(8.1 \%)$ females. Mortality was most common in AAMI $(n=58 ; 19.6 \%)$, followed by AIMI $(n=36$; $17 \%$ ). In regards to major vessel stenosis, mortality occurred most frequently in L2, RCA, and L1, respectively in the decreasing order of frequency. In the group of CAD patients with RSR $>1$, the factors responsible for poor prognosis and causing increased mortality are the presence of TVCAD, high GS, and low EF. The coexistence of these conditions increase the need for these patients to undergo coronary bypass surgery and may contribute to a worse prognosis. I a patient with a confirmed ACS with characteristic clinical manifestations, RSR $>1$ may be an independent predictor of TVCAD and mortality.

\section{Study limitation}

The major limitations of the study were its singlecenter and retrospective design, along with the difficulties in retrieving the data. We could not collect information on the medication use of the patients, any presence of a secondary living, and the risk factors of CAD. The main limitations were inability to collect the ECG and cTn data of the patients after admission to the emergency department and the inpatient hospitalization.

\section{CONCLUSION}

In this study, we found that cTnI, GS, LVEF, TVACD, and mortality increased based on whether the RSR values in the DII lead were lesser or greater than 1 in patients with ACS. Compared to the other groups, the increase in the level of cTnI occurred at a lesser degree in cases with a smaller area of involvement in the myocardium, such as UA. It was observed that the levels of cTnI were elevated more in STEMI compared to those in NSTEMI. These findings suggest that cTnI is correlated with the extent of myocardial involvement in CAD patients in group I with RSR $>1$ and that its levels are elevated in association with the inflammatory events emerging in AMI. In the group with RSR > 1 and above, the number of patients was low and they had a poor prognosis. In this group, 2nd and 3rd degree AV blocks, mortality, TVCAD, AIMI, and
GS were high. In the RSR $<1$ group, the number of patients were higher. The number of complications was higher in this group based on whether the diagnosis was AAMI or NSTEMI. However, the prognosis was good in these patients as GS were lower and LVEF were higher. RSR is similar to cTnI in the sense that it may be a prognostic factor for estimating the complications associated with AMI and for predicting TVCAD and mortality. We are of the opinion that RSR warrants further research in ACS patients.

\section{REFERENCES}

1. Elliot WJ. Cardiovascular risk factors. Which ones can and should be remedied? Postgrad med 1994;96:49-58.

2. Libby P. Current concepts of the pathogenesis of the acute coronary syndromes. Circulation 2001;104:365-72.

3. De Luca G, Suryapranata H, Ottervanger JP, Antman EM. Time delay to treatment and mortality in primary angioplasty for acute myocardial infarction: every minute of delay counts. Circulation 2004;109:1223-5.

4. Antoniucci D, Valenti R, Migliorini A, et al. Relation of time to treatment and mortality in patients with acute myocardial infarction undergoing primary coronary angioplasty. Am J Cardiol 2002;89:1248-52.

5.Libby P. Coronary artery injuty and the biology of atherosclerosis: inflammation, thrombosis, and stabilization. Am J Cardiol. 2000; 86:3-9

6. Morrow DA, Antman EM, Charlesworth A, et al. TIMI risk score for ST-elevation myocardial infarction: A convenient, bedside, clinical score for risk assessment at presentation: An intravenous nPA for treatment of infarcting myocardium early II trial substudy. Circulation 2000;102:2031-7

7. Melgarejo-Moreno A, Galcerá-Tomás J, Garciá-Alberola A, et al. Incidence, clinical characteristics, and prognostic significance of right bundle-branch block in acute myocardial infarction: a study in the thrombolytic era. Circulation 1997;96:1139-44.

8. Ozdemir $\mathrm{K}$, Uluca $\mathrm{Y}$, Daniş $\mathrm{G}$, et al.
Importance of left anterior hemiblock
development in inferior wall acute myocardial
infarction. Angiology 2001;52:743-7.

9.Tan H. Determination of ventricular hypertrophy and chronic cardiomyofibrosis in atrops by means of orthogonal system 
electrocardiography and vecto-cardiography. Associate Professor Thesis. İstanbul 1981.

10.Yılmaz B. Physiology. Feryal Publishing, Ankara, 2000;212-213

11. Kittleson MD Small Animal Cardiovascular Medicine .1998 .

12. Tilley LP, Smith FWK, Oyama MA, Sleeper MM. Manual of Canine and Feline Cardiology. Elsevier Inc, Canada, 2008;49-50

13. Kavsak PA, MacRae AR, Lustig V, et al. The impact of the ESC/ACC redefinition of myocardial infarction and new sensitive troponin assays on the frequency of acute myocardial infarction. Am Heart J 2006;152:118-25.

14. Braunwald E, Antman EM, Beasley JW, et al. ACC/AHA 2002 guideline update for the management of patients with unstable angina and non-ST-segment elevation myocardial infarctionsummary article: a report of the American College of Cardiology/American Heart Association task force on practice guidelines (Committee on the Management of Patients With Unstable Angina). J Am Coll Cardiol 2002;40:1366-74.

15. Bassand JP, Hamm CW, Ardissino D, et al. Guidelines for the diagnosis and treatment of nonST-segment elevation acute coronary syndromes. Task Force for Diagnosis and Treatment of NonST-Segment Elevation Acute Coronary Syndromes of European Society of Cardiology. Eur Heart J 2007;28:1598-660.

16. Panteghini M, Pagani F, Yeo KT, et al. Evaluation of imprecision for cardiac troponin assays at low-range concentrations. Clin Chem 2004;50:327-32.

17.Cannon CP, Braunwald E: Unstable angina. In Braunwald Heart Disease 6 th ed. Philadelphia W. B. Saunders Company 2001:1232-71.

18.AHA/ACC Guideline for the Management of Patients With Non-ST-Elevation Acute Coronary Syndromes. Circulation 2014;130:344-426

19.Gensini GG. A more meaningful scoring system for determining the severity of coronary heart disease. Am J Cardiol 1983;51:606.

20. Rosenbaum MB, Elizari MV, Lazzari JO. The hemiblocks. Oldsmar, FL: Tampa Tracings; 1970.

21. Castellanos A, -Myerburg RJ. The Hemiblocks in Myocardial Infarction. New York: Appleton-Century-Crofts;1976.

22. Kittleson MD Small Animal Cardiovascular Medicine .1998 .
23 Martin M. Small Animal ECGs: An Introductory Guide, Wiley- Blackwell, 2nd ed.2007

24. Fine DM. How to determine and interpret the mean electrical axis. Veterinary medicine, 2006;101(1): 28-36

25. Waldo SW, Brenner DA, Li $\mathrm{S}$, et al. Reperfusion times and in-hospital outcomes among patients with an isolated posterior myocardial infarction: Insights from the National Cardiovascular Data Registry(NCDR). Am Heart J 2014;167:350-4.

26 102. Hamm CW, Ravkilde J, Gerhardt W, et al. The prognostic value of serum troponin $\mathrm{T}$ in unstable angina. N Engl J Med. 1992;327:146-50.

27. Hamm CW, Braunwald E. A classification of unstable angina revisited. Circulation. 2000;102:118-22.

28. Kaul P, Newby LK, Fu Y, et al. Troponin T and quantitative ST-segment depression offer complementary prognostic information in the risk stratification of acute coronary syndrome patients. J Am Coll Cardiol. 2003;41:371-80.

29. Chen Y, Serfass RC, Mackey-Bojack SM, et al. Cardiac troponin $\mathrm{T}$ alterations in myocardium and serum of rats after stressful, prolonged intense exercise. J Appl Physiol. 2000;88:1749-55.

30. Antman EM, Tanasiyevic MJ, Thompson B, et al. Cardiac-spesific troponinI levels to predict the risk of mortality in patients with acute coronary syndrome. N Engl J Med 1996; 335: 1342-9

31. Ohman EM, Amstrong PW, Christenson RH, et al. Cardiac troponin $\mathrm{T}$ levels for riskstratifikasyon in acute myocardial iskemia. GUSTO IIA investigators. N Engl J Med 1966;31;335: 1333-41

32. Morrow DA, Cannon CP, Rifai N, et. al. Ability of minor elevations of troponin $\mathrm{I}$ and $\mathrm{T}$ to identify patients with unstable angina and non-ST elevation myocardial infarction who benefit from an early invasive strategy: Results from a prospective, randomized trial. JAMA. 2001;286:2405-12.

33.Marriott, H. J. L., and Hogan, P. (1970). Hemiblock in acute myocardial infarction. Chest, 58, 342-344.

34.Scheinman, M., and Brenman, B. (1972). Clinical and anatomic implications of intraventricular conduction block in acute myocardial infarction. Circulation, 46, 753-760. 
35.Col, J. J., and Weinberg, S. L. (1972). The incidence and mortality of intraventricular conduction defects in acute myocardial infarction. American Journal of Cardiology, 29, 344-350.

36. Massing GK., and James, T. N. (1971). Anatomical configuration of the His bundle and proximal bundle branches in the human heart. Circulation, 43-44, Suppl. 2, 64.

37. Levy S, Gerard R, Castellanos A Jr., Gharhamani A, Sommer LS. Pure left anterior hemiblock: hemodynamic and arteriographic aspects in patients with coronary artery disease. Eur J Cardiol 1978;8:553-63.

38. Assali A, Sclarovsky S, Herz I, Solodky A, Sulkes J, Strasberg B. Importance of left anterior hemiblock development in inferior Wall acute myocardial infarction. Am J Cardiol 1997;79:672- 4 .

39. Biagini E, Elhendy A, Schinkel AFL, Nelwan S, Rizzello V, van Domburg RT,et al. Prognostic Significance of Left Anterior Hemiblock in Patients With Suspected Coronary Artery Disease. Journal of the American College of Cardiology. 2005; 46(5):858-63

40.Lenegre, J. (1964). Etiology and pathology of bilateral bundlebranch block in relation to complete heart block. Progress in Cardiovascular Diseases, 6, 409-444.

41.Massing, G. K., and James, T. N. (1971). Anatomical configuration of the His bundle and proximal bundle branches in the human heart. Circulation, 43-44, Suppl. 2, 64.

42.Sutton, R., and Davies, M. (1968). The conduction system in acute myocardial infarction complicated by heart block. Circulation, 38, 987992.

43.Scheinman, M., and Brenman, B.(1972). Clinical and anatomic implications of intraventricular conduction blocks in acute myocardial infarction. Circulation, 46, 753.

44. Rizzon, P., Di Biase, M., and Baissus, C. (1974). The intraventricular conduction defects in acute myocardial infarction. British Heart Journal, 36,660 .

45.Rosenbaum MB, Elizari MV, Lazzari JO. The hemiblocks. New concepts of intraventricular conduction based on human anatomical, physiological and clinical studies. Oldsmar, Florida: Tampa Tracings, 1970.
46. Demoulin JC, Kulbertus HE. Histopathological examination of concept of left hemiblock. Br HeartJI 1972; 34: 807-14.

47. Chimient M,Salerno JA, Tavazzi L. Tachycardia-dependent left posterior hemiblock. Br Heart J 1981; 46: 687-90

48. Corne RA, Beamish RE, Rollwagen RL. Significance of left anterior hemiblock. Br Heart J 1978;40:552-7.

49. Yano K, Peskoe SM, Rhoads GG, Moore JO, Kagan A. Left axis deviation and left anterior hemiblock among 8,000 Japanese-American men. Am J Cardiol 1975;35:809 - 15.

50. Ostrander LD Jr. Left axis deviation: prevalence, associated conditions and prognosis. An epidemiologic study. Ann Intern Med 1971;75:23-8.

51. Levy S, Gerard R, Castellanos A, Gharhamani AR, Sommer LS. Transient left anterior hemiblock during angina pectoris: coronarographic aspects and clinical significance. Eur J Cardiol 1979;9:215-25

52.Norris, R. M., and Croxson, M. S. (1970). Bundle-branch block in acute myocardial infarction. American Heart Journal, 79, 728-733.

53.Roos, J. C., and Dunning, A. J. (1970). Right bundle-branch block and left axis deviation in acute myocardial infarction. British Heart Journal, $32,847-851$.

54. Scanlon, P. J., Pryor, R., and Blount, S. G., Jr. (1970). Right bundle-branch block associated with left superior or inferior intraventricular block. Circulation, 42, 1135-1142.

55. Castellanos, A., Maytin, O., Arcebal, A. G., and Lemberg, L. (I970). Significance of complete right bundle-branch block with right axis deviation in absence of right ventricular hypertrophy. British Heart_Journal, 32, 85.

56. Gensini GG. A more meaningful scoring system for determining the severity of coronary heart disease. Am J

Cardiol 1983;51:606.

57. Oishi Y, Wakatsuki T, Nishikado A, Oki T, Ito $\mathrm{S}$. Circulating adhesion molecules and severity of coronary atherosclerosis. Coron Artery Dis 2000;11:77-81.

58. Col, J. J., and Weinberg, S. L. (1972). The incidence and mortality of intraventricular conduction defects in acute myocardial infarction. American Journal of Cardiology, 2g, 344. 
59. Rizzon P, Rossi L, Baissus C, Demoulin JC, Di Biase M. Left posterior hemiblock in acute myocardial infarction. British HeartJournal, I975;37, 711-720.

60Scanlon, P. J., Pryor, R., Blount, S. G. . Right bundle-branch block associated with left superior or inferior intraventricular block. Circulation, 1970;42, II35.

61. Pryor, R., and Blount, S. G. The clinical significance of true left axis deviation. Left intraventricular blocks. American Heart Journal, 1966:72, 391.

62. Voridis, E., Plessas, S., Mallios, K., and Cokkinos, D. (1973). Blocs complets droits et bifasciculaires au cours de la phase aigud de l'infarctus du myocarde. Archives des Maladies du Coeur et des Vaisseaux, 66, II93. 